Article

\title{
Improved Removal of Quinoline from Wastewater Using Coke Powder with Inorganic Ions
}

\author{
Lei Wang ${ }^{1, *}$, Qieyuan Gao ${ }^{1,2}$, Zhipeng $\mathrm{Li}^{1,2}$ and Yongtian Wang ${ }^{1, *}$ \\ 1 National Engineering Research Center of Coal Preparation and Purification, China University of Mining and \\ Technology, Xuzhou 221116, Jiangsu, China; gaoqieyuan@cumt.edu.cn (Q.G.); lizpcumt@126.com (Z.L.) \\ 2 School of Chemical Engineering, China University of Mining and Technology, Xuzhou 221116, Jiangsu, China \\ * Correspondence: lei.wang@cumt.edu.cn (L.W.); wangyt9495@163.com (Y.W.)
}

Received: 15 December 2019; Accepted: 22 January 2020; Published: 27 January 2020

\begin{abstract}
In this paper, laboratory batch adsorption tests were performed to study the adsorption behavior of coke powder in a quinoline aqueous solution with the absence and presence of inorganic ions $\left(\mathrm{K}^{+}\right.$and $\left.\mathrm{Ca}^{2+}\right)$. Adsorption isotherms, thermodynamic parameters, and kinetic models were used to understand the sorption mechanism, and zeta potential measurements were performed to elucidate the effect of the inorganic ions on the adsorption. The results showed that coke powder exhibited a reasonably good adsorption performance due to its pore structure and surface characteristics, and the presence of $\mathrm{K}^{+}$and $\mathrm{Ca}^{2+}$ could further improve the adsorption. Without inorganic ions, the adsorption capacity of coke powder for quinoline and the removal efficiency of quinoline were $1.27 \mathrm{mg} / \mathrm{g}$ and $84.90 \%$, respectively. At the ion concentration of $15 \mathrm{mmol}$, the adsorption capacity of coke powder and quinoline removal efficiency in the presence of $\mathrm{K}^{+}$reached $1.38 \mathrm{mg} / \mathrm{g}$ and $92.02 \%$, respectively, whereas those in the solutions with $\mathrm{Ca}^{2+}$ reached $1.40 \mathrm{mg} / \mathrm{g}$ and $93.31 \%$, respectively. It was found that the adsorption of quinoline onto coke powder in the absence and presence of inorganic ions fit the Freundlich isotherm. Changes in the Gibbs free energy, the heat of adsorption, the entropy, and the activation energy of adsorption suggest that the adsorption was spontaneous and exothermic, which was dominated by physical adsorption, and that the added $\mathrm{K}^{+}$and $\mathrm{Ca}^{2+}$ would favor the adsorption. In addition, the pseudo-second-order kinetic model was found to provide the best fit to the adsorption kinetic data, and $\mathrm{K}^{+}$and $\mathrm{Ca}^{2+}$ increased the rate of quinoline adsorbed onto coke power. This improved adsorption due to inorganic ions was found to be a consequence of the decrease in the surface potential of coke powder particles, which resulted in a reduced thickness of water film around particles, as well as a decreased electrostatic repulsion between coke powder particles and quinoline molecules.
\end{abstract}

Keywords: adsorption; coke powder; quinoline; wastewater treatment; inorganic ions

\section{Introduction}

Wastewater discharged from pesticide, pharmaceutical, and chemical industries usually contain a discernable amount of refractory organic $N$-heterocycles, of which quinoline is a typical example that is known to be carcinogenic, teratogenic, and mutagenic [1-4]. Quinoline is generally thermally stable, and with a strong electronegative $\mathrm{N}$-atom in its heterocycle, it is more water-soluble and diffusive $[5,6]$. Once it enters into the environment, it tends to accumulate and persist in the soil and water, resulting in it being a great danger to the natural environment and human survival $[3,7]$.

To mitigate the detrimental effect of quinoline, attempts of varying degrees of success have been made to remove it from wastewater, and these have involved methodologies mainly including physical methods (e.g., adsorption, filtration, and coagulation) [8,9], chemical methods (e.g., photocatalysis, electrochemistry, and ultrasonic advanced oxidation) [10-12], and biological methods (e.g., aerobic 
degradation, anaerobic degradation, anoxic degradation, and co-matrix degradation) [13-16]. Among these available technologies, the "adsorption" method stands out, as it has the advantage of convenience, easy operation, simplicity of design, and great potential of extensive application in large-scale wastewater treatment [17].

The adsorption method has been extensively employed to remove water particulate matter and refractory organics including quinoline from various forms of wastewater $[18,19]$. It is well known that the adsorption process is a surface phenomenon, which can be generally grouped to physisorption or chemisorption on the basis of the characteristics of interaction between an adsorbent and an adsorbate [20]. It may also occur due to electrostatic attraction [20]. In general, adsorbent is the primary determinant for successful applications of adsorption method in wastewater treatment [17]. In the literature, a number of adsorbents have been investigated with respect to quinoline removal from wastewater, ranging from industrial adsorbents (e.g., silica gel) [21], industrial wastes (e.g., Rundle spent shale and combusted Rundle spent shale) [22,23], and naturally occurring materials (e.g., kaolinite, montmorillonite, sepiolite, palygorskite, and saponite) $[7,24]$ to catalytic materials (e.g., Ti-containing mesoporous molecular sieve, $\mathrm{Pt}, \mathrm{Pd}$, and $\mathrm{Rh}$ ) [25,26]. However, these adsorbents are generally limited due to low removal efficiency, high cost, complexity in preparation, and poor reusability.

In general, a qualified adsorbent requires an excellent sorption properties along with low cost and eco-friendly disposal after use [27]. The literature suggests that coke powder is a promising adsorbent for wastewater treatment [28-30]. Each year, a great amount of coke powder is produced from coking industries, and its price is only one-fifth of that of metallurgical coking coals, approximately [30]. Coke powder has a large specific surface area, and has exhibited a relatively strong adsorption capacity in the treatment of wastewater containing pyridine, phenol, and methylene blue [29,30]. After adsorption, coke powder could be returned to metallurgical process for sustainable use. Due to its excellent mechanical strength and thermal stability, it could also be regenerated by heat treatment to continue the adsorption [28]. However, few studies are available with respect to removing quinoline from wastewater using coke powder.

In addition, a recent study by Bian et al. [31] suggests that inorganic ions could enhance quinoline adsorption. In their study, the effect of $\mathrm{NaCl}$ and $\mathrm{CaCl}_{2}$ on the adsorption of quinoline onto coking coal was investigated. The adsorption capacity of coking coal for quinoline and the removal efficiency of quinoline without inorganic ions were $1.26 \mathrm{mg} / \mathrm{g}$ and $83.87 \%$, respectively. When $\mathrm{NaCl}$ was present in the solution, the adsorption capacity of coking coal and quinoline removal efficiency could reach $1.35 \mathrm{mg} / \mathrm{g}$ and $90.21 \%$, respectively. With the presence of $\mathrm{CaCl}_{2}$, the adsorption capacity of coking coal and quinoline removal efficiency could increase to $1.42 \mathrm{mg} / \mathrm{g}$ and $94.47 \%$, respectively. However, it is still unknown whether inorganic ions also improve the adsorption of quinoline when coke powder is used as the adsorbent.

In this paper, the adsorption of quinoline from aqueous solution onto coke powder in the absence and presence of inorganic ions was investigated. The data were analyzed using the adsorption isotherms, thermodynamic parameters, and kinetic models to understand sorption thermodynamics and kinetics of quinoline adsorbed onto coke powder. Zeta potentials ( $\zeta$-potentials) of coke powder particles in the solution with different inorganic ions were also measured to explain the effect of the inorganic ions on the adsorption.

\section{Materials and Methods}

\subsection{Materials}

The adsorbent used in this study was coke powder (below $0.5 \mathrm{~mm}$ ) obtained from the coking plant of Shandong Rongxin Coal Chemical Industry Group Co., Ltd. (Jining, China). The coke powder was crushed, ground, sieved through a $74 \mu \mathrm{m}$ sieve, and dried at $100{ }^{\circ} \mathrm{C}$ in an oven for $2 \mathrm{~h}$ before use. Figure 1 shows the size distribution of the coke powder which was determined by wet sieving 
the sample using a set of sieves in the range of $74-10 \mu \mathrm{m}$. The error bars are the standard deviation obtained from the triplicate measurements of the particle size.

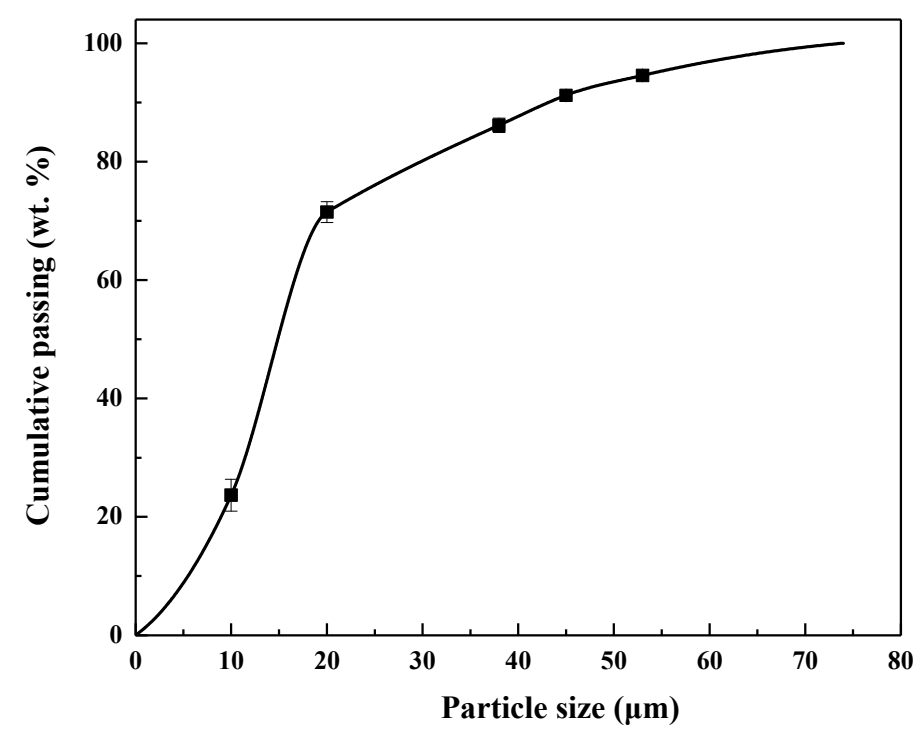

Figure 1. Particle size distribution of coke powder used in this study.

The properties of the coke powder were characterized using X-ray fluorescence (XRF, Model S8 TIGER, Bruker, Karlsruhe, Germany), X-ray diffraction (XRD, Model D8 Advance, Bruker, Karlsruhe, Germany), scanning electron microscopy (SEM, Tecnai G2 F20, FEI, Hillsboro, NH, USA), and Brunauer-Emmett-Teller (BET) method using $\mathrm{N}_{2}$ adsorption (Model BELSORP-max, BEL-JAPAN Inc., Tokyo, Japan).

Quinoline was used as the adsorbate, whereas $\mathrm{KCl}$ and $\mathrm{CaCl}_{2}$ were selected for the investigation of the effect of inorganic ions on the adsorption of quinoline by coke powder. All these chemicals were of analytical reagent (AR) standard, supplied by Sinopharm Chemical Reagent Co., Ltd. (Shanghai, China).

\subsection{Methods}

\subsubsection{Batch Adsorption Tests}

For an adsorption test, a certain amount of quinoline stock solution of $1.00 \mathrm{~g} / \mathrm{L}$ was pipetted to a $100 \mathrm{~mL}$ conical flask. Deionized water was added to the flask to prepare a quinoline solution with a volume of $V(\mathrm{~L})$. The quinoline concentration in this diluted solution was the initial concentration $C_{0}$ $(\mathrm{mg} / \mathrm{L}) . m(\mathrm{~g})$ coke powder was then added to the solution for quinoline adsorption. The conical flask was sealed with a plastic wrap and shaken in a thermostatic water bath shaker with the temperature controlled at $T(\mathrm{~K})$ for $t$ (min). After shaking, the solution was filtered, and the residual quinoline concentration in the filtrate was determined using a UV-VIS spectrophotometer (UV-4802S, Shimadzu, Kyoto, Japan). The maximum absorbance wavelength of quinoline was found to be $278 \mathrm{~nm}$.

The adsorption capacity of the adsorbent and removal efficiency of an adsorbate are two important indicators when investigating the adsorption performance. Equation (1) gives the calculation of the adsorption capacity of coke powder for quinoline, $Q_{\mathrm{t}}(\mathrm{mg} / \mathrm{g})$, at the time $t$ :

$$
Q_{\mathrm{t}}=\frac{\left(C_{0}-C_{t}\right)}{m}
$$

where $C_{t}$ is the quinoline concentration in the solution at the time $t(\mathrm{mg} / \mathrm{L}), V$ is the volume of quinoline solution (L), and $m$ is the dosage of coke powder (g). 
The adsorption capacity of coke powder for quinoline at equilibrium was calculated using Equation (2):

$$
Q_{e}=\frac{\left(C_{0}-C_{e}\right) V}{m}
$$

where $Q_{e}$ is the equilibrium adsorption capacity of coke powder for quinoline $(\mathrm{mg} / \mathrm{g})$, and $C_{e}$ is the residual quinoline concentration in solution at adsorption equilibrium $(\mathrm{mg} / \mathrm{L})$.

Equation (3) shows the calculation of the removal efficiency of quinoline in the solution after time $t, R_{\mathrm{t}}(\%)$

$$
R_{\mathrm{t}}=\frac{\left(C_{0}-C_{t}\right)}{C_{0}} \times 100 .
$$

\subsubsection{Zeta Potential Measurement}

To elucidate the effect of $\mathrm{KCl}$ and $\mathrm{CaCl}_{2}$ on the adsorption of quinoline onto coke powder, zeta potential of coke powder suspensions with different ion concentrations was measured using a $\zeta$-potential analyzer (ZetaPALS, Brookhaven Instruments, New York, NY, USA). Each suspension was prepared to be $50 \mathrm{~mL}$ with a coke powder concentration of $10 \mathrm{~g} / \mathrm{L} . \mathrm{KCl}$ or $\mathrm{CaCl}_{2}$ was then added into the suspension to a required concentration. Prior to measurement, the suspension was stirred at $1600 \mathrm{rpm}$ for $5 \mathrm{~min}$ using a magnetic thermostatic mixer. After $12 \mathrm{~h}, 5 \mathrm{~mL}$ supernatant was transferred to the electrophoresis tank of the $\zeta$-potential analyzer for measurement, without $\mathrm{pH}$ manipulation.

\section{Results and Discussion}

\subsection{Coke Powder Characteristics}

The characteristics of coke powder basically determine its adsorption performance. Table 1 and Figure 2 show the chemical composition of coke powder determined by XRF and XRD. A relatively low content of inorganics was observed in the coke powder, and the main inorganics were aluminum silicate $\left(\mathrm{Al}_{2} \mathrm{SiO}_{5}\right)$ and gesso $\left(\mathrm{CaSO}_{4}\right)$. These clay minerals may have an adsorption effect to a lesser extent due to their lower content [12].

Table 1. Compound contents in the coke powder obtained by X-ray fluorescence (XRF).

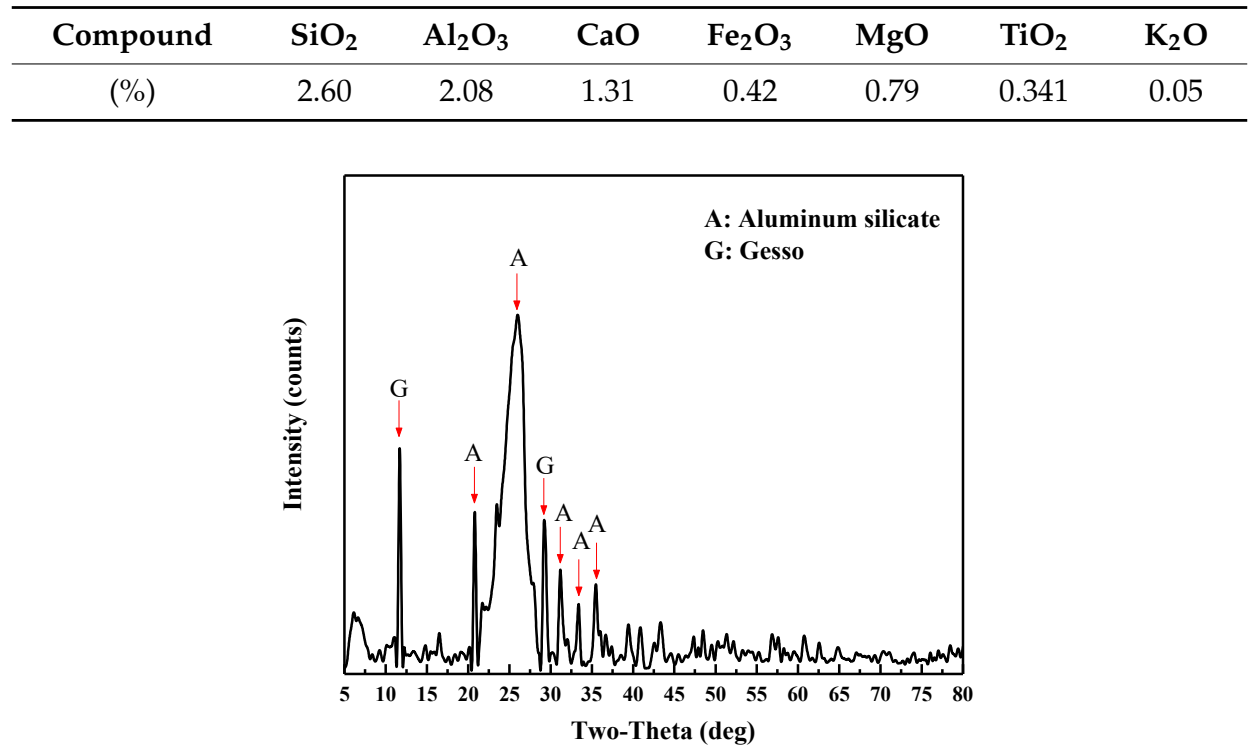

Figure 2. X-ray diffraction (XRD) spectra of the coke powder used in this study.

The surficial morphologies of the coke powder are shown in Figure 3. It can be clearly seen that the surface of coke powder was rough and uneven, with pores existing on the surfaces. Because coke 
powder is produced at high temperature and pressure during the coking process, plugging material in the pore was greatly dissolved. This porous structure on the coke powder surface allowed for an increased possibility of pollutants in wastewater to be adsorbed onto the coke powder.

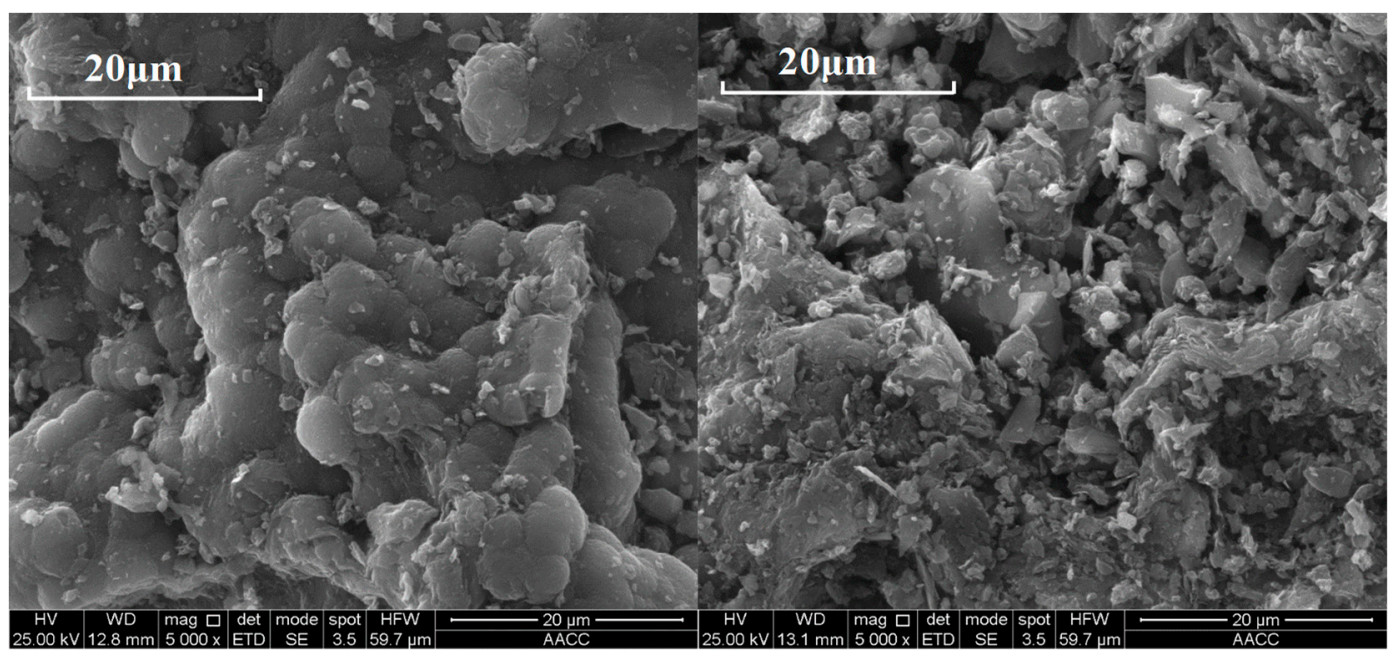

Figure 3. Surface morphologies of the coke powder determined by scanning electron microscopy (SEM).

The pore properties of the adsorbents were then investigated using the Brunauer-Emmett-Teller (BET) analysis, as shown in Table 2. Mesoporous pore structure was found to dominate the coke powder. The specific surface area, average pore size, total pore volume, and mesopore volume of the coke powder were $55.65 \mathrm{~m}^{2} / \mathrm{g}, 7.45 \mathrm{~nm}, 0.029 \mathrm{~cm}^{3} / \mathrm{g}$, and $0.030 \mathrm{~cm}^{3} / \mathrm{g}$, respectively.

Table 2. Pore properties of the coke powder obtained from Brunauer-Emmett-Teller (BET) analysis.

\begin{tabular}{cccc}
\hline $\begin{array}{c}\text { Specific Surface Area } \\
\left(\mathbf{m}^{2} / \mathbf{g}\right)\end{array}$ & $\begin{array}{c}\text { Average Pore } \\
\text { Size }(\mathbf{n m})\end{array}$ & $\begin{array}{c}\text { Mesoporous Volume } \\
\left(\mathbf{c m}^{3} / \mathbf{g}\right)\end{array}$ & $\begin{array}{c}\text { Total Pore Volume } \\
\left(\mathbf{c m}^{3} / \mathbf{g}\right)\end{array}$ \\
\hline 55.65 & 7.45 & 0.029 & 0.030 \\
\hline
\end{tabular}

\subsection{Quinoline Adsorption by Coke Powder with Inorganic Ions}

To study the adsorption performance of coke powder for quinoline removal from wastewater and the effect of inorganic ions on the adsorption, adsorption tests were conducted in the absence and presence of various concentrations of $\mathrm{KCl}$ and $\mathrm{CaCl}_{2}$. The investigated concentration of $\mathrm{K}^{+}$and $\mathrm{Ca}^{2+}$ ranged from 0 to $80 \mathrm{mmol} / \mathrm{L}$. Each adsorption test was performed, in triplicate, at a quinoline concentration of $30 \mathrm{mg} / \mathrm{L}$, a coke powder concentration of $20 \mathrm{~g} / \mathrm{L}$, a contact time of $60 \mathrm{~min}$, and a temperature of $298 \mathrm{~K}$, which were determined using single-factor experiments in the preliminary work. Figure 4 shows the change in adsorption capacity of coke powder for quinoline and quinoline removal efficiency. As can be seen, in the absence of inorganic ions, the adsorption capacity of coke powder for quinoline and the quinoline removal efficiency were $1.27 \mathrm{mg} / \mathrm{g}$ and $84.90 \%$, respectively. This indicates that coke powder could offer a reasonably good adsorption performance when treating quinoline-containing wastewater.

With the addition of inorganic ions, a marked increase was observed in both the adsorption capacity of coke powder and quinoline removal efficiency. Interestingly, there was a rapid increase in both the adsorption performance indicators when the concentration of $\mathrm{K}^{+}$and $\mathrm{Ca}^{2+}$ was increased to $15 \mathrm{mmol} / \mathrm{L}$, after which this increase tended to be slow and steady. At the ion concentration of $15 \mathrm{mmol}$, the adsorption capacity of coke powder and quinoline removal efficiency in the presence of $\mathrm{K}^{+}$reached $1.38 \mathrm{mg} / \mathrm{g}$ and $92.02 \%$, respectively, whereas those in the solutions with $\mathrm{Ca}^{2+}$ reached $1.40 \mathrm{mg} / \mathrm{g}$ and $93.31 \%$, respectively. As indicated in Figure 4, the differences in the adsorption of quinoline onto coke powder in the absence and presence of inorgainic ions showed statistical significance at a probability of $95 \%$. 

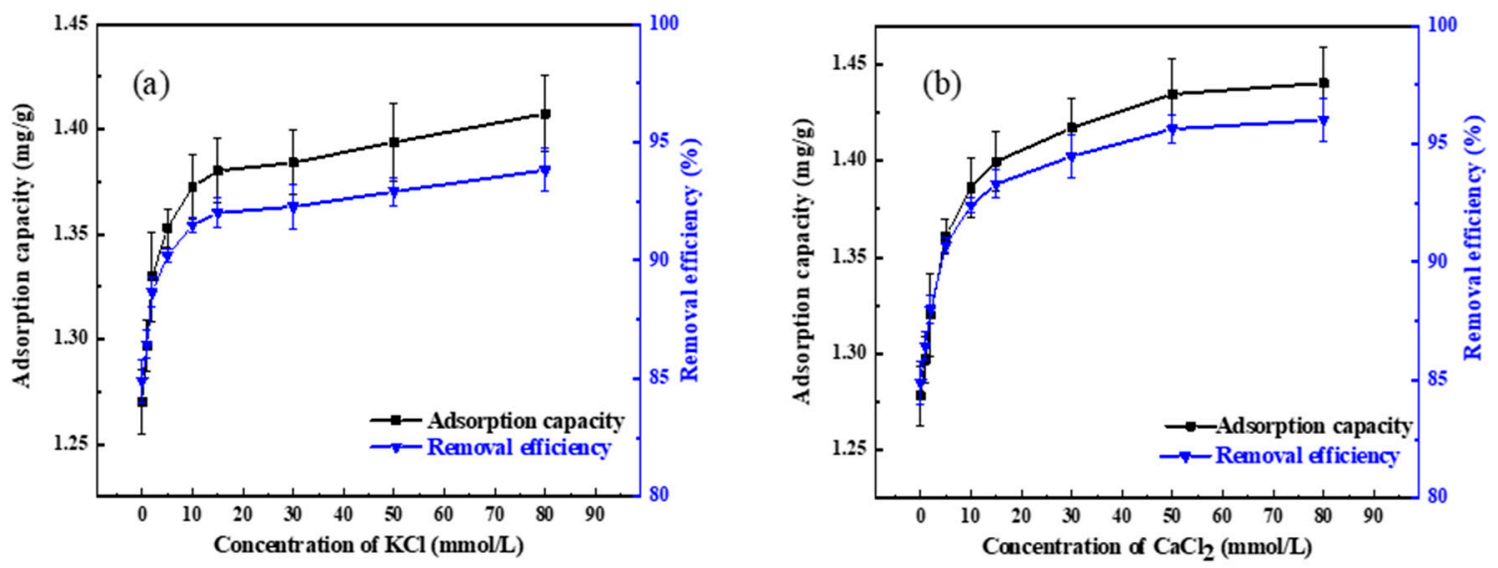

Figure 4. Variations in the adsorption capacity of coke powder and quinoline removal efficiency in the absence and presence of (a) $\mathrm{KCl}$ and (b) $\mathrm{CaCl}_{2}$ (the error bars represent the $95 \%$ confidence interval of the average values).

The improved adsorption performance of coke power for quinoline with inorganic ions was found to be associated with changes in the ionic environment in the vicinity of the charged surface of coke powder particles. It is known that the electrical double layer includes an adsorption layer and a diffusion layer [32]. With the addition of inorganic ions, the diffusion layer would be compressed, and the thickness of the double layer would be decreased, as indicated by the decrease in the surface potential (i.e., zeta potential) of coke powder with the presence of $\mathrm{K}^{+}$and $\mathrm{Ca}^{2+}$ (see Figure 5). On the one hand, this change would result in a reduced thickness of water film surrounding coke powder particles, which tends to be easily disrupted during the oscillation in the water bath shaker, facilitating the motion of quinoline molecules onto the coke powder surface [33]. On the other hand, the reduced surface potential of coke powder particles would decrease the electrostatic repulsion between coke powder particles and quinoline molecules, which was beneficial for the adsorption of quinoline onto coke powder.

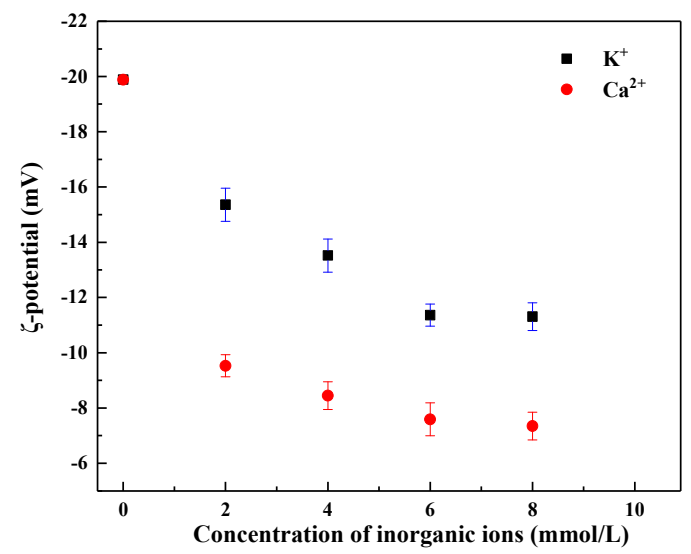

Figure 5. $\zeta$-potential of coke powder in solutions with various concentrations of inorganic ions (the error bars represent the standard deviation obtained from measurements in triplicate).

In addition, due probably to the ion solvation, inorganic ions may also reduce the free water in the aqueous solution, resulting in a relative increment of quinoline concentration that favored the adsorption of quinoline onto coke powder [34].

Interestingly, $\mathrm{K}^{+}$and $\mathrm{Ca}^{2+}$ appeared to result in a similar effect when improving the adsorption of quinoline onto coke powder, although $\mathrm{Ca}^{2+}$ provided a more positive charge than $\mathrm{K}^{+}$at the same concentration. This may be attributed to the difference in the ionic activity of $\mathrm{K}^{+}$and $\mathrm{Ca}^{2+}$ in the 
aqueous solution. Both $\mathrm{KCl}$ and $\mathrm{CaCl}_{2}$ are known to be strong electrolytes. Due to the hydrolysis, however, the ionic activity of $\mathrm{Ca}^{2+}$ in the aqueous solution would tend to decrease to some extent. Thus, this superiority of $\mathrm{Ca}^{2+}$ in the charge number was counteracted somewhat by its decreased ionic activity, leading to a similar positive effect on the adsorption of quinoline onto coke powder.

Moreover, when the concentrations of the inorganic ions exceeded $15 \mathrm{mmol} / \mathrm{L}$, the $\mathrm{K}^{+}$and $\mathrm{Ca}^{2+}$ adsorbed in the Stern layer of the double layer may have been dense enough that only a few more of them could have fitted in by increasing their concentration. This may explain why there was a slight increase in the adsorption capacity of coke powder and quinoline removal efficiency after the ion concentration exceeded $15 \mathrm{mmol} / \mathrm{L}$.

\subsection{Adsorption Isotherm Modelling}

Adsorption isotherm describes the relationship between the quantity of adsorbate adsorbed onto the adsorbent and the concentration of adsorbate dissolved in the liquid phase at equilibrium, suggesting the essence of the adsorption phenomenon as well as adsorbent characteristics. In this study, three equililbrium isotherm models_-Langmuir, Freundlich, and Temkin isotherms [35-37]—were tested for their applicability to represent the experimental data using non-linear regression fit. The expression of these isotherms is shown in Table 3.

Table 3. The expression of the Langmuir, Freundlich, and Temkin isotherms.

\begin{tabular}{cll}
\hline Isotherms & \multicolumn{1}{c}{ Equations } & \multicolumn{1}{c}{ Parameters } \\
\hline Langmuir & $Q_{e}=\frac{K_{L} q_{m} C_{e}}{1+K_{L} C_{e}}$ & $\begin{array}{l}K_{L}(\mathrm{~L} / \mathrm{mg}): \text { Langmuir adsorption constant } \\
q_{m}(\mathrm{mg} / \mathrm{g}): \text { monolayer adsorption capacity }\end{array}$ \\
\hline \multirow{2}{*}{ Freundlich } & $Q_{e}=K_{F} C_{e}^{\frac{1}{n}}$ & $\begin{array}{l}K_{F}(\mathrm{~L} / \mathrm{mg}): \text { Freundlich adsorption constant } \\
1 / n: \text { parameter for evaluating the level of adsorption }\end{array}$ \\
\hline \multirow{2}{*}{ Temkin } & $Q_{e}=\left(\frac{R T}{b_{T}}\right) \ln \left(K_{T} C_{e}\right)$ & $\begin{array}{l}T(\mathrm{~K}): \text { absolute temperature } \\
\end{array}$ \\
& $K_{T}(\mathrm{~L} / \mathrm{mg}):$ adsorption constant \\
& $b_{T}(\mathrm{KJ} / \mathrm{mol}):$ a parameter related to adsorption heat \\
\hline
\end{tabular}

The isothermal adsorption tests were performed in the absence and presence of $\mathrm{K}^{+}$and $\mathrm{Ca}^{2+}$ at 298, 303, and $313 \mathrm{~K}$. In each test, $1 \mathrm{~g}$ of coke powder was added to a $50 \mathrm{~mL}$ solution with the required quinoline concentration, which was initially set at $5,10,20,30$, and $50 \mathrm{mg} / \mathrm{L}$. The concentration of both $\mathrm{K}^{+}$and $\mathrm{Ca}^{2+}$ was kept at $15 \mathrm{mmol} / \mathrm{L}$. Each isothermal adsorption test was performed in triplicate. Table 4 summarizes the results obtained from fitting the Langmuir, Freundlich, and Temkin isotherm models to the experimental adsorption data. The errors for each parameter represent the $95 \%$ confidence interval of the average values. As suggested from the $R^{2}$ values in Table 4 , the Freundlich isotherm model provided the best fit to the adsorption data at all temperatures. This shows that the Freundlich isotherm model could account for the adsorption isotherm data with the highest accuracy, implying that the adsorption occurred by the formation of multilayers. Figure 6 shows the results of fitting the Freundlich isotherm model to the experimental adsorption data.

The obtained $1 / n$ values for the Freundlich isothermal adsorption model as shown in Table 4 were found to be less than 1 , indicating that the adsorption of quinoline onto coke powder is favorable in the absence and presence of inorganic ions. The $K_{F}$ value is the parameter associated with adsorption capacity, and a larger $K_{F}$ value generally represents a better adsorption capacity of adsorbents, which has been used to compare the adsorption performance of different adsorbents in a number of studies $[12,31,38,39]$. In this study, the $K_{F}$ value was found to be higher at the lowest temperature (293 K). This is in consistence with the observation that the adsorption capacity of coke powder for quinoline increased with decreasing the temperature from 313 to $293 \mathrm{~K}$, as shown in Figure 6. In addition, the presence of inorganic ions further increased the $K_{F}$ value at the lowest temperature, suggesting that these inorganic ions favor the adsorption of quinoline onto coke powder. 
Table 4. Summary of results from the equilibrium isotherm model fitting.

\begin{tabular}{|c|c|c|c|c|c|c|c|c|c|c|}
\hline \multirow{3}{*}{ Isotherms } & \multirow{3}{*}{ Parameters } & \multicolumn{3}{|c|}{ No Inorganic Ions } & \multicolumn{3}{|c|}{$\mathrm{KCl}$} & \multicolumn{3}{|c|}{$\mathrm{CaCl}_{2}$} \\
\hline & & \multicolumn{3}{|c|}{ Temperature (K) } & \multicolumn{3}{|c|}{ Temperature (K) } & \multicolumn{3}{|c|}{ Temperature (K) } \\
\hline & & 293 & 303 & 313 & 293 & 303 & 313 & 293 & 303 & 313 \\
\hline \multirow{3}{*}{ Langmuir } & $K_{L}(\mathrm{~L} / \mathrm{mg})$ & $0.2160 \pm 0.0092$ & $0.0932 \pm 0.0064$ & $0.0295 \pm 0.0030$ & $0.2916 \pm 0.0130$ & $0.0797 \pm 0.0017$ & $0.0418 \pm 0.0042$ & $0.4998 \pm 0.0055$ & $0.1881 \pm 0.0041$ & $0.0656 \pm 0.0026$ \\
\hline & $q_{m}(\mathrm{mg} / \mathrm{g})$ & $3.6030 \pm 0.0498$ & $4.7583 \pm 0.1846$ & $9.7203 \pm 0.8711$ & $3.3258 \pm 0.0882$ & $5.7627 \pm 0.0778$ & $7.7392 \pm 0.4763$ & $3.0436 \pm 0.0185$ & $3.9499 \pm 0.0610$ & $6.3187 \pm 0.0918$ \\
\hline & $R^{2}$ & 0.9539 & 0.9933 & 0.9988 & 0.9354 & 0.9908 & 0.9983 & 0.8851 & 0.9664 & 0.9975 \\
\hline \multirow{3}{*}{ Freundlich } & $K_{F}(\mathrm{~L} / \mathrm{mg})$ & $0.7708 \pm 0.0059$ & $0.4775 \pm 0.0128$ & $0.3006 \pm 0.0092$ & $0.8688 \pm 0.0092$ & $0.5060 \pm 0.0078$ & $0.3469 \pm 0.0174$ & $1.0949 \pm 0.0123$ & $0.7475 \pm 0.0012$ & $0.4565 \pm 0.0127$ \\
\hline & $1 / n$ & $0.5281 \pm 0.0013$ & $0.6974 \pm 0.0126$ & $0.8745 \pm 0.0107$ & $0.4843 \pm 0.0109$ & $0.7148 \pm 0.0050$ & $0.8261 \pm 0.0180$ & $0.4025 \pm 0.0021$ & $0.5594 \pm 0.0029$ & $0.7482 \pm 0.0081$ \\
\hline & $R^{2}$ & 0.9892 & 0.9985 & 0.9970 & 0.9852 & 0.9988 & 0.9983 & 0.9718 & 0.9937 & 0.9998 \\
\hline \multirow{3}{*}{ Temkin } & $K_{T}(\mathrm{~L} / \mathrm{mg})$ & $5.1109 \pm 0.4431$ & $1.9851 \pm 0.0477$ & $1.0946 \pm 0.0040$ & $5.3997 \pm 0.5527$ & $1.5638 \pm 0.0134$ & $1.2089 \pm 0.0152$ & $9.6520 \pm 0.2926$ & $2.7686 \pm 0.0873$ & $1.1937 \pm 0.0075$ \\
\hline & $b_{T}(\mathrm{KJ} / \mathrm{mol})$ & $42.5716 \pm 1.6799$ & $36.6732 \pm 0.3924$ & $31.9177 \pm 0.4899$ & $41.3435 \pm 1.7288$ & $29.8692 \pm 0.0695$ & $32.0165 \pm 0.3123$ & $44.5572 \pm 0.4651$ & $34.3601 \pm 0.6169$ & $27.8543 \pm 0.2673$ \\
\hline & $R^{2}$ & 0.8857 & 0.9283 & 0.9449 & 0.8938 & 0.9351 & 0.9488 & 0.8743 & 0.9257 & 0.9592 \\
\hline
\end{tabular}



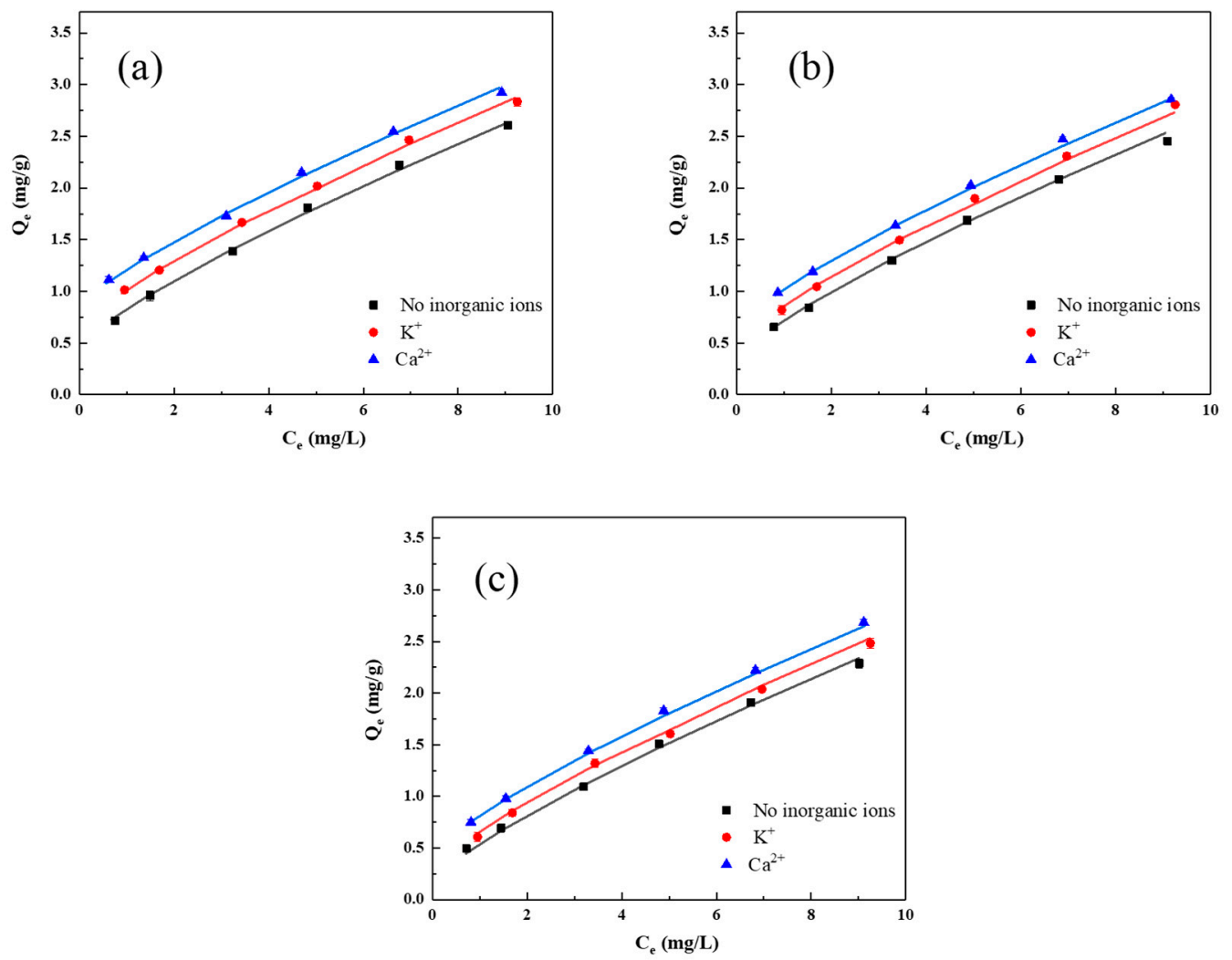

Figure 6. Results of fitting the Freundlich isotherm model to the experimental adsorption data: (a) $293 \mathrm{~K}$, (b) $303 \mathrm{~K}$, and (c) $313 \mathrm{~K}$ (the error bars represent the $95 \%$ confidence interval of the average values).

\subsection{Adsorption Thermodynamic Parameters}

The thermodynamic parameters including the change in the Gibbs free energy, heat of adsorption, as well as the entropy for the adsorption of quinoline onto coke powder in the absence and presence inorganic ions were investigated to better understand the adsorption process. The Gibbs free energy, which indicates the degree of the spontaneity, is given as

$$
\Delta G^{\circ}=-R T \ln K
$$

where $\Delta G^{\circ}$ is the Gibbs free energy change $(\mathrm{kJ} / \mathrm{mol}), R$ is the ideal gas constant $(R=8.314 \mathrm{~J} /(\mathrm{mol} \cdot \mathrm{K})), T$ is the absolute temperature $(\mathrm{K})$, and $K$ is the partition coefficient.

At a constant temperature, the change in Gibbs free energy is a function of changes in the heat of adsorption and the entropy:

$$
\Delta G^{\circ}=\Delta H^{\circ}-T \Delta S^{\circ}
$$

where $\Delta H^{\circ}$ is the enthalpy change $(\mathrm{kJ} / \mathrm{mol})$, and $\Delta S^{\circ}$ is the entropy change $(\mathrm{kJ} / \mathrm{mol})$.

Combining Equations (4) and (5) gives:

$$
-\ln K=-\frac{\Delta H^{\circ}}{R T}+\frac{\Delta S^{\circ}}{R} .
$$

The $\ln K$ values in the absence and presence of inorganic ions at different temperatures were obtained from the intercept of the straight line by plotting $\ln \left(Q_{e} / C_{e}\right)$ against $Q_{e}$, a method proposed by Khan and Singh [40] that has been adopted in a number of studies [12,31,41,42]. The values of $\Delta H^{\circ}$ and $\Delta S^{\circ}$ were obtained by plotting the $\ln K$ values against $1 / T$ (see Equation (6)), and thus $\Delta G^{\circ}$ could be obtained using Equation (5). The results of these obtained thermodynamic parameters are shown in Table 5. 
Table 5. Thermodynamic parameters for the adsorption of quinoline onto coke powder.

\begin{tabular}{cccccccccc}
\hline \multirow{2}{*}{ Parameters } & \multicolumn{3}{c}{ No Inorganic Ions } & \multicolumn{3}{c}{$\mathbf{K C l}$} & \multicolumn{3}{c}{$\mathrm{CaCl}_{\mathbf{2}}$} \\
\cline { 2 - 11 } & \multicolumn{3}{c}{ Temperature (K) } & \multicolumn{2}{c}{ Temperature (K) } & \multicolumn{2}{c}{ Temperature (K) } \\
\cline { 2 - 11 } & $\mathbf{2 9 3}$ & $\mathbf{3 0 3}$ & $\mathbf{3 1 3}$ & $\mathbf{2 9 3}$ & $\mathbf{3 0 3}$ & $\mathbf{3 1 3}$ & $\mathbf{2 9 3}$ & $\mathbf{3 0 3}$ & $\mathbf{3 1 3}$ \\
\hline $\ln K$ & 3.83 & 3.71 & 3.42 & 4.59 & 4.12 & 3.86 & 5.82 & 4.77 & 4.47 \\
$\Delta H^{\circ}(\mathrm{kJ} / \mathrm{mol})$ & & -6.45 & & & -13.13 & & & -16.25 & \\
$\Delta S^{\circ}(\mathrm{J} / \mathrm{mol} \cdot \mathrm{K})$ & & -9.36 & & & -28.75 & & & -37.27 & \\
$\Delta G^{\circ}(\mathrm{kJ} / \mathrm{mol})$ & -3.50 & -3.62 & -3.73 & -4.56 & -4.72 & -4.87 & -4.79 & -4.96 & -5.12 \\
\hline
\end{tabular}

It can be clearly seen that the value of $\Delta G^{\circ}$ in each isothermal adsorption test was negative, showing that the adsorption of quinoline onto coke powder was spontaneous, irrespective of the presence of absence of inorganic ions. Instead, the addition of inorganic ions increased the absolute values of $\Delta G^{\circ}$, resulting in a more favorable adsorption of quinoline onto coke powder.

The relatively low negative values of $\Delta H^{\circ}$ indicated that the adsorption of quinoline by coke powder was exothermic, which was dominated by physical adsorption. A low temperature would favor the adsorption of quinoline onto coke powder, as observed in Figure 6. In addition, the decreased adsorption entropy may suggest that coke powder particles limited the motion of quinoline molecules by adsorbing them on their surface. The increased absolute value of entropy with the presence of inorganic ions also suggests the positive effect of these ions on the quinoline adsorption.

\subsection{Adsorption Kinetics}

To study the kinetics of the adsorption of quinoline onto coke powder in the absence and presence of inorganic ions, adsorption tests were conducted at different contact times ranging from 10 to $120 \mathrm{~min}$. The concentrations of quinolone, coke powder, and inorganic ions $\left(\mathrm{K}^{+}\right.$and $\left.\mathrm{Ca}^{2+}\right)$ used were $30 \mathrm{mg} / \mathrm{L}$, $20 \mathrm{~g} / \mathrm{L}$, and $15 \mathrm{mmol} / \mathrm{L}$, respectively. Figure 7 shows the adsorption capacity of coke powder for quinoline with contact time set at 293, 303, and $313 \mathrm{~K}$. As can be seen, the adsorption capacity of coke powder increased with increasing contact time and reached equilibrium at $60 \mathrm{~min}$ of adsorption, irrespective of the presence or absence of inorganic ions. The addition of the inorganic ions further increased the adsorption capacity of coke powder for quinoline in the initial $60 \mathrm{~min}$ of adsorption. The adsorption capacity was found to increase sharply in the initial 30 min of adsorption, which may have been associated with a greater number of vacant surficial sites available for adsorption at the initial stage of the adsorption [39]. This increase then gradually slowed down, probably due to the depletion of most of the vacant adsorptive sites on the surface and long range diffusion of quinoline molecules onto the interior pores of the coke powder [39], ultimately terminating at 60 min where the adsorption capacity leveled off.

Two kinetic models, the pseudo-first-order model and the pseudo-second-order model, were used to test their applicability to represent the experimental adsorption kinetic data. The pseudo-first-order model is given as [43]:

$$
Q_{t}=Q_{e}\left(1-e^{-k_{1} t}\right)
$$

where $k_{1}$ is the rate constant of pseudo-first-order adsorption $\left(\mathrm{min}^{-1}\right)$.

The pseudo-second-order model is express as [43]:

$$
Q_{t}=\frac{t k_{s} Q_{e}^{2}}{1+t k_{s} Q_{e}}
$$

where $k_{2}$ is the rate constant of pseudo-second-order adsorption $(\mathrm{g} /(\mathrm{mg} \cdot \mathrm{min}))$. The initial adsorption rate $h(\mathrm{mg} /(\mathrm{g} \cdot \mathrm{min}))$, at $t \rightarrow 0$, is related to the rate constant $k_{2}$ and the adsorption capacity at equilibrium $Q_{\mathrm{e}}$ :

$$
h=k_{2} \times Q_{e}^{2} .
$$



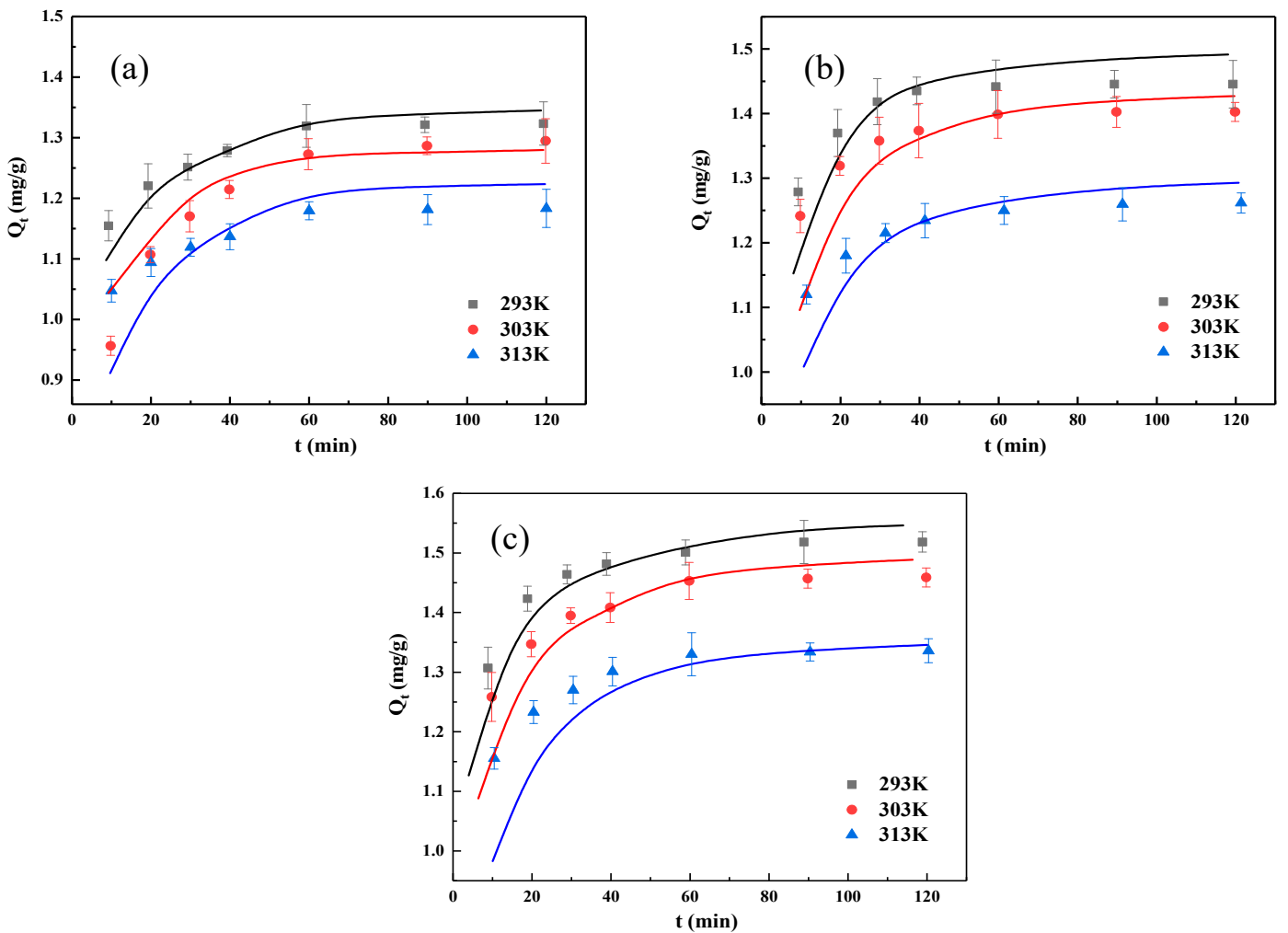

Figure 7. The effect of contact time on the adsorption capacity of coke powder for quinoline with (a) no inorganic ions, (b) $\mathrm{K}^{+}$, and (c) $\mathrm{Ca}^{2+}$ (experimental data points given by symbols and the lines predicated using the pseudo-second-order model; the error bars represent the standard deviation calculated on the basis of the adsorption tests performed in triplicate in this study).

Table 6 shows the results of fitting these two kinetic models to the experimental adsorption kinetic data. The $R^{2}$ values indicate that the pseudo-second-order model provides the best fit to the adsorption data. As shown in Table 6 , the $k_{2}$ values were observed as decreasing with the addition of inorganic ions. $k_{2}$ represents the consumption of an adsorbent for the adsorption of a unit of an adsorbate in a fixed time. Thus, the decrease in the $k_{2}$ values with the presence of inorganic ions suggests an increase in the adsorption rate of quinoline onto coke powder.

Table 6. Kinetic parameters for the adsorption of quinoline onto coke powder.

\begin{tabular}{|c|c|c|c|c|c|c|c|c|c|c|}
\hline \multirow{2}{*}{ Kinetic Model } & \multirow{2}{*}{ Parameters } & \multicolumn{3}{|c|}{$\begin{array}{c}\text { No Inorganic Ions } \\
\text { Temperature (K) }\end{array}$} & \multicolumn{3}{|c|}{$\mathrm{KCl}$} & \multicolumn{3}{|c|}{$\mathrm{CaCl}_{2}$} \\
\hline & & 293 & 303 & 313 & 293 & 303 & 313 & 293 & 303 & 313 \\
\hline \multirow{3}{*}{$\begin{array}{l}\text { Pseudo-first-order } \\
\text { model }\end{array}$} & $Q_{e(\exp )}(\mathrm{mg} / \mathrm{g})$ & 1.26 & 1.24 & 1.22 & 1.38 & 1.35 & 1.31 & 1.42 & 1.41 & 1.37 \\
\hline & $Q_{e(c a l)}(\mathrm{mg} / \mathrm{g})$ & 0.17 & 0.15 & 0.13 & 0.10 & 0.13 & 0.14 & 0.17 & 0.17 & 0.17 \\
\hline & $k_{1}\left(\min ^{-1}\right)$ & 0.0297 & 0.0290 & 0.0218 & 0.0294 & 0.0274 & 0.0297 & 0.0253 & 0.0301 & 0.0322 \\
\hline \multirow{3}{*}{$\begin{array}{l}\text { Pseudo-second-order } \\
\text { model }\end{array}$} & $k_{2}(\mathrm{~g} /(\mathrm{mg} \cdot \mathrm{min}))$ & 0.4405 & 0.7232 & 0.7678 & 0.4423 & 0.4662 & 0.5472 & 0.3494 & 0.3670 & 0.4104 \\
\hline & $h(\mathrm{mg} /(\mathrm{g} \cdot \mathrm{min}))$ & 0.719 & 0.892 & 1.135 & 0.887 & 0.880 & 0.966 & 0.732 & 0.751 & 0.797 \\
\hline & $R^{2}$ & 0.9641 & 0.9308 & 0.8446 & 0.9802 & 0.9941 & 0.9892 & 0.9973 & 0.9873 & 0.9840 \\
\hline
\end{tabular}

Because the adsorption of quinoline onto coke powder corresponded to the pseudo-second-order model, activation energy was estimated by fitting the Arrhenius formula (Equation (10)) to the adsorption kinetic data reported in Table 6 [42]. Activation energy describes the degree of difficulty in proceeding the adsorption, and it could provide insights into understanding the adsorption of quinoline onto coke powder in the absence and presence of inorganic ions. 


$$
k_{2}=k_{0} e^{\left(-\frac{E_{a}}{R T}\right)}
$$

where $k_{2}$ is the rate constant of pseudo-second-order adsorption $(\mathrm{g} /(\mathrm{mg} \cdot \mathrm{min})), k_{0}$ is the pre-exponential factor, and $E_{a}$ is activation energy $(\mathrm{KJ} / \mathrm{mol})$.

The activation energies for the quinoline adsorption in the absence of inorganic ions and in the presence of $\mathrm{K}^{+}$and $\mathrm{Ca}^{2+}$ were found to be $9.36,8.22$, and $5.12 \mathrm{~kJ} / \mathrm{mol}$, respectively. The activation energy required for physical adsorption is small, usually in the range of $5-40 \mathrm{~kJ} / \mathrm{mol}$ [12]. The result indicates that the physical adsorption dominated the adsorption of quinoline onto coke powder, which agrees with inference from the small change in the heat of adsorption. The values of activation energy for adsorption associated with $\mathrm{K}^{+}$and $\mathrm{Ca}^{2+}$ were found to be smaller, verifying again that inorganic inorganic ions favor the adsorption of quinoline onto coke powder.

\section{Conclusions}

In this study, the adsorption behavior of coke powder in a quinoline aqueous solution with the absence and presence of inorganic ions $\left(\mathrm{K}^{+}\right.$and $\left.\mathrm{Ca}^{2+}\right)$ was investigated in a batch system. The obtained experimental results and data analysis performed allow the following conclusions to be drawn:

(1) Coke powder exhibited a reasonably good adsorption performance in the treatment of aqueous solution containing quinoline due to its pore structure and surface characteristics, and this adsorption could be further improved by the presence of $\mathrm{K}^{+}$and $\mathrm{Ca}^{2+}$.

(2) Freundlich isotherm was found to best fit the experimental data obtained from the adsorption tests in the absence and presence of inorganic ions. The adsorption thermodynamic analysis for $\Delta G^{\circ}$, $\Delta H^{\circ}, \Delta S^{\circ}$, and $E_{a}$ suggested that adsorption of quinoline onto coke powder was spontaneous and exothermic, which was dominated by physical adsorption. The addition of inorganic ions would increase the absolute values of $\Delta G^{\circ}$ and $\Delta H^{\circ}$, and decrease the $\Delta S^{\circ}$ and activation energy $E_{a}$ for qunoline adsorption, suggesting a beneficial effect of $\mathrm{K}^{+}$and $\mathrm{Ca}^{2+}$ on the quinoline adsorption.

(3) The adsorption of quinoline onto coke powder in the absence and presence of inorganic ions was found to correspond to the pseudo-second-order model, and the presence of $\mathrm{K}^{+}$and $\mathrm{Ca}^{2+}$ increased the rate of quinoline adsorbed onto coke powder.

(4) $\mathrm{K}^{+}$and $\mathrm{Ca}^{2+}$ were found to reduce the surface potential of coke powder particles and the thickness of water film surrounding them, facilitating the motion of quinoline molecules onto the coke powder surface. In addition, the reduced surface potential of coke powder particles would also decrease the electrostatic repulsion between coal particles and quinoline molecules, which was favorable for the adsorption of quinoline onto coke powder.

Author Contributions: Conceptualization, Q.G. and L.W.; methodology, Q.G. and Z.L.; writing-original draft preparation, Q.G.; writing-review and editing, L.W.; resources, Y.W. All authors have read and agreed to the published version of the manuscript.

Funding: This research was funded by the Fundamental Research Funds for the Central Universities (no. 2018QNA29).

Acknowledgments: The funding provided by the Fundamental Research Funds for the Central Universities (no. 2018QNA29), which made this work possible, is greatly acknowledged.

Conflicts of Interest: The authors declare no conflicts of interest.

\section{References}

1. Jing, J.Y.; Li, W.Y.; Boyd, A.; Zhang, Y.; Colvin, V.L.; Yu, W.W. Photocatalytic degradation of quinoline in aqueous $\mathrm{TiO}_{2}$ suspension. J. Hazard. Mater. 2012, 237, 247-255. [CrossRef] [PubMed]

2. Padoley, K.V.; Mudliar, S.N.; Pandey, R.A. Heterocyclic nitrogenous pollutants in the environment and their treatment options-An overview. Bioresour. Technol. 2008, 99, 4029-4043. [CrossRef] [PubMed]

3. Wang, C.R.; Ma, K.K.; Wu, T.T.; Ye, M.; Tan, P.; Yan, K.C. Electrochemical mineralization pathway of quinoline by boron-Doped diamond anodes. Chemosphere 2016, 149, 219-223. [CrossRef] 
4. Zhu, H.; Ma, W.C.; Han, H.J.; Han, Y.X.; Ma, W.W. Catalytic ozonation of quinoline using Nano-MgO: Efficacy, pathways, mechanisms and its application to real biologically pretreated coal gasification wastewater. Chem. Eng. J. 2017, 327, 91-99. [CrossRef]

5. Erdogan, S.; Safi, Z.S.; Kaya, S.; Isin, D.O.; Guo, L.; Kaya, C. A computational study on corrosion inhibition performances of novel quinoline derivatives against the corrosion of iron. J. Mol. Strcut. 2017, 1134, 751-761. [CrossRef]

6. Ferreira, M.E.D.; Vaz, B.G.; Borba, C.E.; Alonso, C.G.; Ostroski, I.C. Modified activated carbon as a promising adsorbent for quinoline removal. Micropor. Mesopor. Mater. 2019, 277, 208-216. [CrossRef]

7. Burgos, W.; Nipon, P.; Mazzarese, M.C.; Chorover, J. Adsorption of quinoline to kaolinite and montmorillonite. Environ. Eng. Sci. 2002, 19, 59-68. [CrossRef]

8. Kuang, L.K.; Ming, L.I. Recovering pyridine from industrial waste water by means of continuous distillation. Pesticides 2005, 02, 69-71.

9. Lataye, D.H.; Mishra, I.M.; Mall, I.D. Removal of pyridine from aqueous solution by adsorption on bagasse fly ash. Ind. Eng. Chem. Res. 2006, 45, 3934-3943. [CrossRef]

10. Gosu, V.; Gurjar, B.R.; Rao, Y.S.; Zhang, T.C. Treatment of pyridine-Bearing wastewater by nano zero-Valent iron supported on activated carbon derived from agricultural waste. Desalin. Water Treat. 2016, 57, 1-11. [CrossRef]

11. Padoley, K.V.; Mudliar, S.N.; Banerjee, S.K. Fenton oxidation: A pretreatment option for improved biological treatment of pyridine and 3-Cyanopyridine plant wastewater. Chem. Eng. J. 2011, 166, 1-9. [CrossRef]

12. Xu, H.X.; Huang, G.; Li, X.B.; Gao, L.H.; Wang, Y.T. Removal of Quinoline from aqueous solutions by lignite, coking coal and anthracite. Adsorption asotherms and thermodynamics. Physicochem. Probl. Miner. 2016, 52, 214-227.

13. Khasaeva, F.; Vasilyuk, N.; Terentyev, P.; Troshina, M.; Lebedev, A.T. A novel soil bacterial strain degrading pyridines. Environ. Chem. Lett. 2011, 9, 439-445. [CrossRef]

14. Kim, M.K.; Singleton, I.; Yin, C.R.; Quan, Z.X.; Lee, M.; Lee, S.T. Influence of phenol on the biodegradation of pyridine by freely suspended and immobilized pseudomonas putida mk1. Lett. Appl. Microbiol. 2010, 42, 495-500. [CrossRef]

15. Mohan, S.V.; Sistla, S.; Guru, R.K.; Prasad, K.K.; Kumar, C.S.; Ramakrishna, S.V. Microbial degradation of pyridine using pseudomonas sp. and isolation of plasmid responsible for degradation. Waste Manag. 2003, 23, 167-171. [CrossRef]

16. Watson, G.K.; Cain, R.B. Microbial metabolism of the pyridine ring. metabolic pathways of pyridine biodegradation by soil bacteria. Biochem. J. 1975, 146, 157-172. [CrossRef]

17. Kalebaila, K.K.; Kenneth, J.M.; Misheck, M. Selected Adsorbents for Removal of Contaminants from Wastewater: Towards Engineering Clay Minerals. Open J. Appl. Sci. 2018, 08, 355-369.

18. Aksu, Z.; Yener, J. A comparative adsorption/biosorption study of mono-Chlorinated phenols onto various sorbents. Waste Manag. 2001, 21, 695-697. [CrossRef]

19. Badmus, M.A.O.; Audu, T.O.K. Periwinkle shell based granular activated carbon for treatment of chemical oxygen demand (COD) in industrial wastewater. Can. J. Chem. Eng. 2009, 87, 69-71. [CrossRef]

20. Crini, G. Selected adsorbents for removal of contaminants from wastewater: Towards engineering clay minerals non-Conventional low-Cost adsorbents for dye removal: A review. Bioresour. Technol. 2006, 97, 1061-1085. [CrossRef]

21. Moon, J.K.; Keum, D.K.; Lee, W.K. Adsorption equilibria for m-Cresol, quinoline, and 1-Naphthol onto silica gel. Korean J. Chem. Eng. 1989, 6, 172-178. [CrossRef]

22. Zhu, S.; Bell, P.R.F.; Greenfield, P.F. Adsorption of pyridine onto spent Rundle oil shale in dilute aqueous solution. Water Res. 1988, 22, 1331-1337. [CrossRef]

23. Zhu, S.; Bell, P.R.F.; Greenfield, P.F. Quinoline adsorption onto combusted rundle spent shale in dilute aqueous solution at the natural $\mathrm{pH}$ 8. Water Res. 1995, 29, 1393-1400. [CrossRef]

24. Vico, L.I.; Acebal, S.G. Some aspects about the adsorption of quinoline on fibrous silicates and Patagonian saponite. Appl. Clay Sci. 2006, 33, 142-148. [CrossRef]

25. Santarossa, G.; Iannuzzi, M.; Vargas, A.; Baiker, A. Adsorption of Naphthalene and quinoline on Pt, Pd and Rh: A DFT study. Chem. Phys. 2008, 9, 401-413. [CrossRef] [PubMed]

26. Zhang, H.; Li, G.; Jia, Y.H.; Liu, H.O. Adsorptive removal of nitrogen-Containing compounds from fuel. J. Chem. Eng. Data 2010, 55, 173-177. [CrossRef] 
27. Wang, N.N.; Zhao, Q.; Xu, H.; Niu, W.Y.; Ma, L.; Lan, D.C.; Hao, L.L. Adsorptive treatment of coking wastewater using raw coal fly ash: Adsorption kinetic, thermodynamics and regeneration by fenton process. Chemosphere 2018, 210, 624-632. [CrossRef]

28. Gao, Q.Y.; Wang, L.; Li, Z.P.; Xie, Y.Q.; He, Q.Q.; Wang, Y.T. Adsorptive removal of pyridine in simulation wastewater using coke powder. Processes 2019, 7, 459. [CrossRef]

29. Luo, H.M.; Yu, H.M.; Feng, H.X.; Zhang, J.Q.; Zhao, X.; Wang, Y. The mechanism and properties of methylene blue adsorption on modified coke powder. J. China Coal Soc. 2009, 34, 971-976.

30. Shen, L.F.; Shen, Y.P.; Liu, W.X.; Niu, H.F.; Li, Y. Treatment of coking wastewater by physicochemical-Hydrolytic acidification-A/O combined process. Technol. Water Treat. 2007, 9, 90-93.

31. Bian, Y.; Sun, H.; Luo, Y.X.; Gao, Q.Y.; Li, G.S.; Wang, Y.T. Effect of inorganic salt ions on the adsorption of quinoline using coal powder. Water Sci. Technol. 2018, 78, 496-505. [CrossRef] [PubMed]

32. Oldham, K.B. A Gouy-Chapman-Stern model of the double layer at a (metal)/(ionic liquid) interface. J. Electroanal. Chem. 2008, 613, 131-138. [CrossRef]

33. Zhang, R.; Guo, F.Y.; Xia, Y.C.; Tan, J.L.; Xing, Y.W.; Gui, X.H. Recovering unburned carbon from gasification fly ash using saline water. Waste Manag. 2019, 98, 29-36. [CrossRef] [PubMed]

34. Arafat, H.A.; Marcus, F.A.; Pinto, N.G. Effect of Salt on the Mechanism of Adsorption of Aromatics on Activated Carbon. Langmuir 1999, 15, 5997-6003. [CrossRef]

35. Freundlich, H.M.F. Over the adsorption in solution. J. Phys. Chem. 1906, 57, 385-471.

36. Langmuir, I. The Adsorption of gases on plane surfaces of glass, mica and platinum. J. Am. Chem. Soc. 1918, 40, 1361-1403. [CrossRef]

37. Temkin, M.J.; Pyzhev, V. Kinetics of ammonia synthesis on promoted iron catalysts. Acta Physiochim. URSS. 1940, 12, 217-222.

38. Kim, Y.S.; Kim, J.H. Isotherm, kinetic and thermodynamic studies on the adsorption of paclitaxel onto Sylopute. J. Chem. Thermodyn. 2019, 130, 104-113. [CrossRef]

39. Rameshraja, D.; Srivastava, V.C.; Kushwaha, J.P.; Mall, I.D. Quinoline adsorption onto granular activated carbon and bagasse fly ash. Chem. Eng. J. 2012, 181, 343-351. [CrossRef]

40. Khan, A.A.; Singh, R.P. Adsorption thermodynamics of carbofuran on $\mathrm{Sn}(\mathrm{IV})$ arsenosilicate in $\mathrm{H}^{+}, \mathrm{Na}^{+}$, and $\mathrm{Ca}^{2+}$ forms. Colloids Surf. 1987, 24, 33-42. [CrossRef]

41. Shu, Y.H.; Jia, X.S. The mechanisms for CTMAB-Bentonites to adsorb CBs from water in the adsorption kinetics and thermodynamics view. Acta Sci. Circumstantiae 2005, 25, 1530-1536.

42. Chandra, T.C.; Mirna, M.M.; Suaryanto, Y.; Ismadji, S. Adsorption of basic dye onto activated carbon prepared from durian shell: Studies of adsorption equilibrium and kinetics. Chem. Eng. J. 2007, 127, 121-129. [CrossRef]

43. Ho, Y.S.; Mckay, G.A. Comparison of chemisorption kinetic models applied to pollutant removal on various sorbents. Process Saf. Environ. Prot. 1998, 76, 332-340. [CrossRef] 